This article seeks to understand the place of the work called Taa da Dvida in the career of the Romanian artist, Victor Brauner. The artist, who is considered one of the most talented painters in the École de Paris, belonged to the French surrealistic group, and created a hybrid vocabulary, linked to different mystical traditions and to the influence of other modern artists. Taa da Dvida belongs to MASP (São Paulo Art Museum), and, an excellent opportunity arises from this Brazilian heritage of understanding the poetical visual of this unique artist.

Keywords: Victor Brauner, surrealistic art, collection 


\title{
Victor Brauner: interpretações de uma obra do patrimônio museal brasileiro*
}

\author{
Emerson Dionisio Gomes de \\ OLIVEIRA
}

O presente artigo procura compreender o lugar da obra Taa da Dvida na carreira do artista romeno Victor Brauner. Considerado um dos mais talentosos pintores da Escola de Paris, o artista, que pertenceu ao grupo surrealista francês, criou um vocabulário híbrido, vinculado a diferentes tradições místicas e às influências de outros artistas modernos. Taa da Dvida pertence ao acervo do Museu de Arte de São Paulo, e, a partir desse patrimônio brasileiro, surge uma excelente oportunidade de se compreender a poética visual desse artista ímpar.

Palavras-chave: Victor Brauner, arte surrealista, acervo 
O romeno Victor Brauner ainda é um artista que ocupa uma posição secundária na história da arte européia. Seu papel está circunscrito à identificação de sua obra pictórica àquela "administrada" pelo grupo surrealista francês, movimento que o acolheu entre 1932 e 1943 e que produziu forte impacto na maturidade de sua arte, mas que, todavia, não foi capaz de explicar a poética produzida pelo artista a partir dos anos 40. O presente artigo procura estudar uma obra desse momento: Taça da Dúvida. Trata-se de uma das duas peças do artista adquiridas pelo Museu de Arte de São Paulo (Masp) em 1947 e que fazem parte de seu acervo.

Outro objetivo deste artigo - talvez o mais útil - é apresentar Victor Brauner, por meio de uma análise histórica e crítica de Taça da Dúvida, obra executada pelo pintor romeno em 1946 e adquirida pelo Masp juntamente com outra peça do pintor, datada do mesmo ano: Arquitetura Pentacular. Ambas entraram no museu em 3 de outubro de 1947, compradas por intermédio de Assis Chateaubriand, com capital da empresa Alto Madeira S.A., quando expostas em abril de 1947, na galeria Julian Levy, em Nova York. 1

O interesse por Taça da Dúvida (fig.1) e a ênfase dada a ela significaram procurar nexos históricos, simbólicos e estilísticos em outras obras do próprio pintor, pois parte vital de nosso método está na constituição de séries de obras capazes de estabelecer, tanto estética como historicamente, um panorama mais amplo das condições de produção da obra.

O universo artístico de Brauner é, de certa forma, atípico, mesmo para aqueles habituados com a estética surrealista predominante. Adentrar no

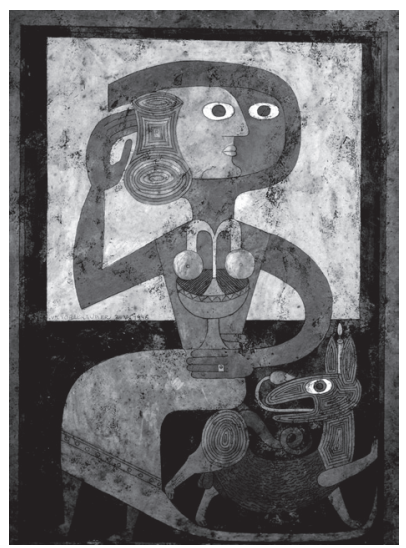

Fig. 1- Taça da dúvida, 1946 . Cera sobre madeira. $64 \times 49 \mathrm{~cm}$. Museu de Arte de São Paulo. mundo místico e simbólico do pintor romeno exige uma compreensão para além do limitado programa surrealista engenhado por André Breton e seus companheiros (BRETON 1979; 1985; 1986; 1988). Antes buscamos compreender a obra do Masp a partir da pluralidade de influências religiosas e literárias que matizaram o pensamento do artista e que esta- 
vam indicadas tanto em outras obras quanto em textos auxiliares advindos de cartas e manifestos confessionais.

Brauner nasceu romeno, em 1903, filho de pais judeus, que logo se entregaram aos mais variados grupos místicos de forte cunho espiritualista: uma moda bastante disseminada nos grandes centros da Europa Central e Oriental no final do século XIX. Essa incursão religiosa de sua família foi a mais importante influência de sua infância para sua arte. As investidas religiosas, principalmente do pai, tiveram uma séria projeção sobre a personalidade de Victor. Vidência e comunicação com o reino do além-túmulo deram-no uma forte impressão das dimensões da vida depois da morte, além de um profundo sentido de "destino" (DANCER, 1996).

Em Viena, onde a família estabeleceu-se em 1912, Victor Brauner foi identificado como um médium de grande valor em sessões espíritas para crianças. Tal revelação acentuou sua busca de experiências com o "não-real" (GAUNT,1973, p.244). Não podemos nos de esquecer que Brauner sempre teve uma supersensibilidade para com os fenômenos que não podiam ser explicados pela simples lógica; seus trabalhos apresentam uma obsessão pela magia, pela esquizofrenia (lida por ele não como uma páthos) e por fenômenos paranormais, todos estimulados por experiências vividas na primeira infância e na juventude.

Como podemos perceber pelo modo como seus biógrafos e estudiosos narram sua infância, Brauner não evitou enfrentar, como artista, um dos principais dilemas do misticismo: a comunicação da experiência com o divino por meio da arte. O artista descobriu muito cedo que quanto mais intenso e profundo é o contato com o sobrenatural, tanto menos é suscetível de definição objetiva, pois sua própria natureza transcende a categoria sujeito e objeto até então definidos. É nesse hiato que a arte surrealista e "primitiva" - obras de Klee, De Chirico, Brancusi e outros - surge para criar uma cultura do mundo mágico, cara ao romeno (VANCI-PERAHIM, 1995). Cultura lida como escrita secreta capaz de exprimir a experiência com o sobrenatural. Embora não tenhamos encontrado uma definição exata de arte dada pelo artista romeno, ficamos tentados a supor que ele vê a arte como parte da experiência mística e, por conseguinte, 
uma linguagem acessível apenas a iniciados.

Taça da Dúvida (Coupe de Doute) é um exemplo nítido das experiências artísticas de caráter espiritual de Brauner. A obra é uma pintura a cera (eucatex) sobre pergaminho, assentada em madeira com $0,64 \times 0,49 \mathrm{~cm}$ e com peso aproximado de 3 quilos. Não está assinada e possui, sobre a sua superfície, no canto inferior direito, a seguinte data: 02. V. 1946. O valor atribuído à Taça da Dúvida foi o de $\mathrm{Cr} \$ 200.000,00$ no momento de sua compra.

A composição de Taça da Dúvida é, de certo modo, clara. $\mathrm{Na}$ obra existe uma figura feminina acompanhada de um animal semelhante a um cão. As duas personagens são construídas através de estruturas levemente geométricas, ou seja, são utilizadas as figuras básicas da geometria tradicional - círculo, triângulo, quadrado e retângulo - para compor o quadro. As linhas curvilíneas abertas, fechadas e retilíneas se mantêm em toda a composição, o que lhe confere o rigor encontrado em muitas obras de inúmeras culturas ditas primitivas.

Como podemos notar, a obra é dividida em duas partes. A maior, que toma aproximadamente cerca 55\% do quadro, está na parte superior, iluminada pela prevalência do dourado ao fundo. A menor delimita o campo inferior, matizado pelo marrom. A figura feminina encontra-se nas duas partes, enquanto o cão à sua direita está na parte inferior.

Tanto o cão quanto a figura feminina foram pintados de perfil, com uma organização típica dos ícones, da arte egípcia, das representações da arte bizantina e pré-colombiana. A cabeça da figura humana é formada pela união de duas faces, uma de perfil e a outra frontal2. Em cada face existe um olho. Há um "campo" que sai do pescoço e envolve as faces fundidas da personagem. Com essa fusão, Brauner exerce sua capacidade de conferir à figura um caráter simbólico, que revela um "olhar" tão presente na história de sua arte, como trataremos adiante.

A figura feminina segura com a mão direita uma taça, da qual jorra, como numa fonte d'água, uma solução que termina por constituir, num plano de imagens duplas, os seios da própria personagem. Toda composição da taça, que dá o nome 
à obra, com esse caráter ambíguo, duvidoso, está construída num jogo perspectivo diverso do resto da composição, no plano inferior, onde encontramos as pernas da personagem e o cão.

O "segundo-terceiro" olho, resultado da fusão das duas faces sobrepostas, e a taça não se revelam como os únicos signos com uma longa tradição simbólica. Existe, também, uma pequena vela acesa no alto da cabeça do cão e um anel na mão que segura o utensílio. Perspectiva, disposição, jogo de duplos, o olho da face tratada em dois momentos, a vela, o anel e, sobretudo, a taça são elementos que invocam o enredo de um enigma que evoca as tradições da cartomancia, em especial da tradição do tarô-cigano medieval, conhecida, imitada e relida pelo artista em muitas outras obras.

O quadro do Masp é constituído dentro de uma bidimensionalidade, que só não é austera porque o pintor inseriu, ao fundo, na parte superior, o dourado. Com esse contrataste cromático e linhas muito tênues, que parecem não deter a projeção da personagem para um primeiro plano, Brauner lançou mão de um jogo próprio da tradição bizantina, que habitava parte considerável da arte popular e religiosa de seu país natal.

As cores predominantes são o dourado, os vermelhos, o marrom, o ocre e o azul, com detalhes em verde e anil. As cores quentes predominam, contudo, estão vaporizadas, graças às características da técnica a cera, por meio da qual se dilui o pigmento cromático na parafina. A técnica a cera não é casual. Ela surge da necessidade de substituir as tintas durante a II Guerra Mundial, momento em que Brauner encontra-se auto-exilado na Suíça. Ao mesmo tempo, abre um dos capítulos mais criativos de sua carreira, uma vez que lhe surgem novas possibilidades de manipular sua imaginação e suas relações espirituais: "A matéria é minha memória" (apud SEMIN, 1990, p.24), escreve Brauner, numa alusão à obra Matéria e Memória (1896), de Henri Bergson, a quem conhecia e admirava.

\section{O segundo-terceiro olho}

Brauner não foi um homem de uma só obsessão, mas há 
uma que pode facilmente ser compreendida por meio de sua obra e de sua biografia: a significação do olhar3. Em entrevista concedida a Alain Jouffroy sobre um quadro chamado L'anarchie hypnotique, de 1948, Brauner diz:

On peut évidemment se demander pourquoi les yeux rappellent le mystère intérieur d'un être. Mais l'œil est vraiment la chose la plus affolante: il reste la clé du mystère d'un être. (...) C'est le regard qui est la chose la plus bouleversante (1995, p.26-27)4.

Essa necessidade de compreender o olhar nasceu a partir de um auto-retrato pintado em 1931 (fig.2), que consiste num pequeno quadro a óleo sobre madeira, no qual em lugar do olho esquerdo existe uma sombra, um tumor que se expande diante do espectador.

Esse quadro colocou o nome de Victor Brauner em praticamente todas as importantes obras biográficas do movimento surrealista francês. Ele não representa nenhuma inovação na estética do pintor romeno, nem provavelmente seria considerada uma obra importante caso o pintor, anos após tê-la executado, não tivesse perdido o olho esquerdo, retratado dilacerado em 1931. Fato determinante que merece ser explicitado.

Em 1938, no mês de agosto, Brauner realiza

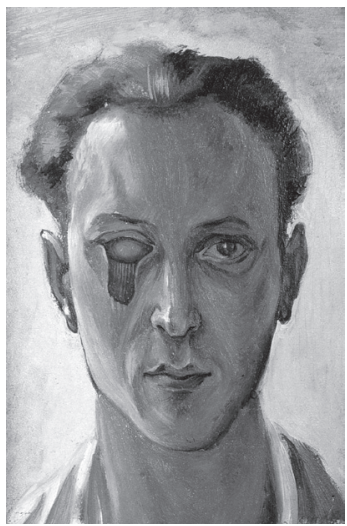

Fig.2- Auto-retrato 1931. Óleo sobre madeira. $22 \mathrm{x}$ $16,2 \mathrm{~cm}$. Musée National d'Art Moderne. Centre Georges Pompidou, Paris. um outro trabalho ao qual intitula de Autoportrait à oeil énucléé. O motivo deste último quadro é o mesmo de 1931. Dias depois, na madrugada do dia 28, Brauner tenta separar uma briga entre Oscar Dominguez e Esteban Francès. No meio da discussão, Dominguez acabou atingindo o olho esquerdo do pintor romeno com uma garrafa. O incidente custou a Brauner a perda total da visão e disseminou, no mundo das artes, o mito do pintor vidente, que, anos antes, havia previsto a fatalidade. O acontecimento marcou definitivamente o papel que o surrealismo concedeu ao pintor de Pietra-Neamtz. Sua experiência premonitória, que, para ele, não era novidade, confirmava-se diante dos artistas que respeitavam a eminência 
do mistério e do acaso (ALEXANDRIAN, 1974, p.26).

Pierre Mabille, em 1939, escreve um artigo denominado L'oeil du peintre na revista Minotaure $n .0$ 12-13, no qual defende que as principais mudanças na carreira de Brauner, nos últimos dois anos, eram conseqüências imediatas de duas perdas, segundo ele, irrevogáveis: a saída definitiva de seu país natal e a perda do olho esquerdo, ambas em 1938. Mabille escreve que "(...) L'homme que je connaissais avant l'accident était effacé, timide, pessimiste, démoralisé par son dernier séjour en Roumanie, il est aujourd'hui délivré, affirmant avec clarté et autorité ses idées, il travaile avec une vigueur nouvelle et atteint davantage son but"5 (apud Dancer, 1996, p.13). É evidente que perder um dos olhos, para quem, desde criança, acreditava ter o dom da terceira visão, não foi nada corriqueiro. Os reflexos em sua obra de arte foram imediatos. O principal deles foi a modificação do espaço, tido como muito clássico por críticos como Mabille (apud Picon, 1976, p. 168), e um lento e gradativo afastamento do grupo surrealista, com o desligamento oficial em 1943.

A idéia do olho como centro místico e canal para o espírito é, sem dúvida, de inspiração romântica, e isto sempre perseguiu Brauner. Como as lendárias bruxas-videntes dos Cárpatos, Brauner tornou-se um homem com um só olho, com uma visão precária da realidade física, mas um ser privilegiado diante dos mistérios do mundo, segundo sua crença (JUDLOVÁ \& ROUSOVÁ, 1996, p.17).

Nos dois anos anteriores ao acidente e, principalmente, depois dele, suas pesquisas sobre mistérios gnósticos tomam um impulso vertiginoso. Sua relação com a arte primitiva modifica-se. Ele não se vê mais como um admirador externo à obra, ele quer tornar-se um co-autor de novas essências primitivas, uma leitura interior do processo artístico que resultou nas obras vindas principalmente da Oceania e das Américas. Nessa mudança, a representação do olho é fundamental.

Após o acidente, os olhos continuavam a merecer destaque em suas pinturas e desenhos. Contudo, o tom não é mais apenas o da angústia. O desespero e o enigmático permanecem, mas, a partir de 1939, o "olho-olhar" surge ao lado de outras 
significações possíveis para indicar, por exemplo, o fantasmagórico, a memória, o desejo e a magia alquimíco-cabalística. Nessa ótica, encontramos obras como o desenho sem título de 1941, em que podemos ver um personagem de perfil com duas cabeças fundidas. Numa dessas cabeças o olho está aberto e, na outra, fechado. Não podemos afirmar que esta é a primeira obra em que Brauner funde duas cabeças numa só. Mas podemos dizer que isso só ocorre após 1938, segundo o julgamento de Jouffroy (1996) e de Semin (1990).

Em outros dois desenhos também sem títulos, datados de 1942, encontramos a fusão (fig.3). Entretanto, nessas obras, já podemos caracterizar as personagens como femininas. As semelhanças com Taça da Dúvida já são mais concretas. No primeiro desenho, existem quatro rostos, dois fundidos num plano inferior e outros dois no superior. Os olhos dos rostos na parte de baixo estão fechados, e os olhos na parte superior estão abertos. No segundo desenho, encontramos uma fusão diferente; nele há no rosto em perfil sobreposto num rosto frontal a mesma lógica encontrada em Taça da Dúvida. A diferença está na inversão dos rostos encontrados na obra do MASP. Em ambos os desenhos de 1942 os seios também são destacados ao lado dos olhos.

Menos óbvio, o quadro La Palladiste ou Composition sur le thème de La Palladiste, de 1943, é uma pequena comédia sobre a anatomia humana (fig.4). A Palladiste é uma figura típica do início dos anos 40 na obra de Brauner. Ela se caracteriza pela disject membra, ou seja, os membros estão

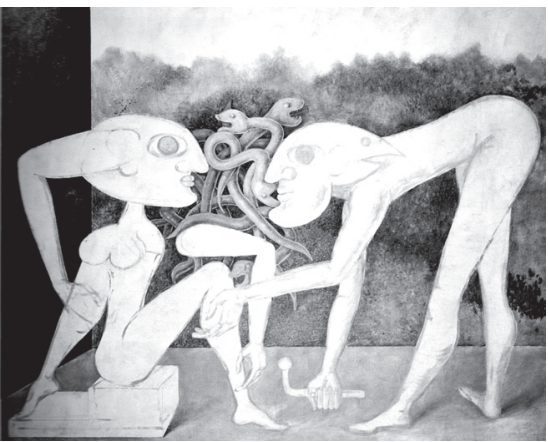

Fig.4- La Palladiste ou Composition sur le thème de la Palladiste, 1943. Óleo sobre tela. M.N. A. M, Paris. 
deslocados do tronco, transgredindo, assim, as leis anatômicas que, para Brauner, mereciam ser subvertidas. Brauner interpreta de modo pessoal esses seres mágicos como Apolonio de Tyane ou Hermes. Na obra há dois personagens, um feminino e outro masculino, no primeiro plano; no plano médio, um emaranhado de serpentes e, no fundo, a folhagem. A primeira figura está sentada sobre uma base, enquanto a segunda, com uma dupla cabeça, está reclinada para a primeira.

Como verificamos, a partir da década de quarenta, os personagens de Brauner perdem um olho, mas, para não abusar da deformação, ele utiliza alguns recursos. O mais usado e aqui presente é o perfil. Os olhos das Palladiste rompem o espaço teoricamente dedicado a eles; são desproporcionais, sem nenhuma novidade para entidades com essas características. O importante é que os olhos aqui representados foram repetidos por muitos anos; possuem o mesmo contorno que a personagem feminina do quadro Taça da Dúvida. A mesma desproporção podemos encontrar em outro importante trabalho sem título de Brauner, datado de 1941. Consiste numa figura em que a cabeça é o corpo de um peixe, ou seja, duas imagens sobrepostas, que seguram um outro peixe. Na cabeça de perfil, o olho é novamente o centro da obra. 6

Não é prudente construir uma retrospectiva exata do formato do olho encontrado em Taça da Dúvida porque Brauner desenha de diferentes maneiras os olhos; ora ele utiliza dois círculos simples (como na obra do MASP e na La Palladiste), ora três círculos, em que o mais interior é deslocado para o lado superior. Muitas vezes ele apenas delimita com lápis o local do olho, sem fazer qualquer distinção naturalista entre íris e o contorno do globo ocular, com ou sem a indicação dos cílios. De qualquer modo, Taça da Dúvida está inserida em uma lógica obsessiva, que, por toda a obra de Brauner a partir de 1931, privilegiou o "olho-olhar", e que o acidente de 1938 só veio a confirmar.

\section{Femininos}

A construção do restante do rosto e do corpo da perso- 
nagem feminina de Taça da Dúvida pode ser encontrada em outros trabalhos de Brauner. O rosto configurado pelo artista no quadro do MASP é constituído de linhas bastante simples, à exceção do detalhe ornamental à esquerda na cabeça da personagem. Esse modo rápido de construir um rosto, com elementos simples, pode ser encontrado em toda sua obra e migrou lentamente do vocabulário gráfico para o pictórico. Poderíamos dar mais exemplos de obras em que o mesmo princípio pode ser encontrado, mas, como o número não é pequeno, optamos por trabalhar apenas com as obras que são realmente próximas à analisada.

As duas primeiras obras podem ser, atualmente, consideradas antecessoras da produção de Taça da Dúvida, não que isso as transforme em quadros preparatórios, pois eles possuem motivos e formas tão díspares do quadro do Masp quanto semeIhanças. Ambas são produzidas pela técnica a cera e nanquim sobre papel. Foram datadas em 07 de abril de 1946 (pouco menos de um mês antes da obra do museu paulista) e, nos dois casos, encontramos, excetuando-se pequenos detalhes, praticamente o mesmo desenho da cabeça de Taça da Dúvida.

No primeiro quadro (fig.5) existe a presença de uma personagem, que não podemos identificar se é ou não feminina, com o rosto em perfil e a cabeça voltada para a direita. A cabeça é cortada por uma espécie de mastro, que conduz a um pescoço e daí para o tronco da figura. Este último é representado por meio da mesma forma geométrica que o tronco da figura principal em Taça. O resto do corpo não guarda semelhanças, pois os membros inferiores estão deslocados para a direita, de modo que a figura se pareça com uma dobradura, e ela não possui as vestes da personagem de Taça. Nesta figura os braços são longos e elásticos. Existem ainda símbolos no quadro que são estranhos ao exemplar pintado quase um mês depois, além da im-

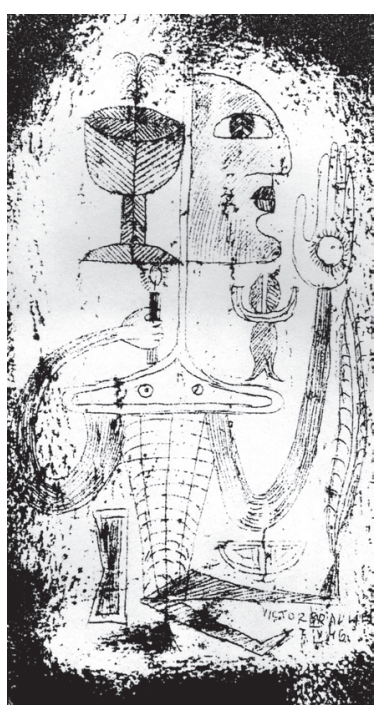

Fig.5 - Sem título. 1946. Nanquim e cera sobre papel, $31,1 \times 24,6 \mathrm{~cm}$. M. A. M. SaintEtienne. portante presença de uma vela e de uma taça. 
O segundo quadro, também Sem Título (fig.6), está mais próximo de Taça da Dúvida. Nele encontramos, do lado direito, uma figura, aparentemente masculina (existe uma sutil referência ao sexo da personagem), que foi desenhada de modo diverso das imagens que estamos tratando nesse estudo. Trata-se de um desenho ligeiro e pouco preocupado com o acabamento das formas. Do seu lado, à esquerda, encontramos uma personagem feminina, que é uma síntese entre o que observamos no quadro anterior e o que podemos encontrar no quadro do Masp. Muito mais elaborada que seu par à direita, essa figura está em pé. Seu corpo é alongado e, no tronco, não há indicação dos seios. Brauner

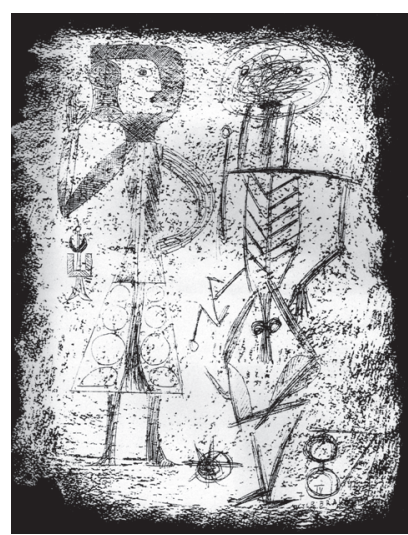

Fig. 6 - Sem título. 1946.

Nanquim e cera sobre papel, 31,1 $\times 25 \mathrm{~cm}$. M.A.M. Saint-Etienne. representou-a com uma saia "decorada" com círculos. Os braços são elásticos como os da obra anterior. As semelhanças com Taça estão na cabeça. É o único desenho em que podemos encontrar

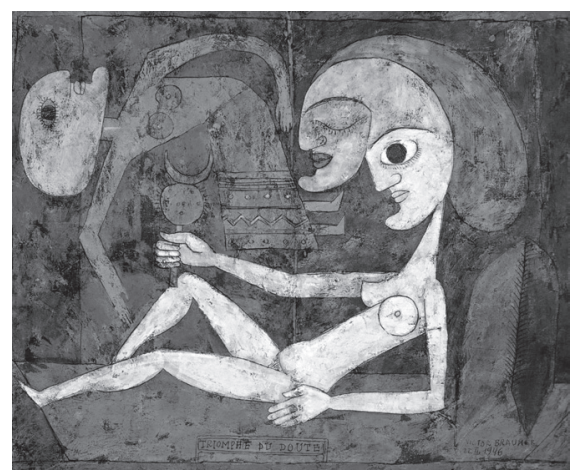

Fig. 7 - O Triunfo da dúvida, 1946. Óleo e cera sobre tela, $81,1 \times 101,1 \mathrm{~cm}$. Coleção Particular. um campo que cerca a cabeça e onde surge o motivo decorativo à direita ao lado do rosto. É verdade que, estruturalmente, tanto o campo quanto o motivo são diferentes, mas sua localização em relação à cabeça é a mesma. Os olhos, o queixo e a boca são semelhantes. Tanto esse quanto o outro trabalho podem ser colocados ao lado de Taça da Dúvida com essas afinidades e diferenças, mas não são comparáveis à obra do Masp no que concerne a seu acabamento e ao cuidado com a execução do quadro.

O mesmo não pode ser dito de O Triunfo da Dúvida (fig.7), quadro produzido com a técnica a cera, de maio de 19467. Sua 
execução é tão primorosa quanto a obra do museu brasileiro. O título é um dos mais próximos que encontramos de Taça da Dúvida. O Triunfo reúne duas personagens femininas semelhantes a trabalhos anteriores. A figura maior é da mesma natureza indicada anteriormente num desenho sem título de 1941. Trata-se de uma personagem com duas cabeças fundidas, em que se pode ver um rosto com o olho aberto e outro com o olho fechado. Sobre as duas cabeças, existe um prolongamento do "crânio", que pode ser ou não o cabelo. Ela deita-se com seu corpo delgado sobre uma base que não é identificável e segura com a mão direita uma espécie de cetro, que parece sustentar a segunda personagem. Esta última guarda semelhanças com a personagem de Taça. Sua cabeça é da mesma natureza que a cabeça em perfil da obra estudada. O corpo é semelhante, principalmente o recorte da saia. A figura secundária está suspensa no ar e dobrada na mesma lógica que o primeiro quadro produzido em 07 de abril.

A última produção que podemos apresentar como descendente das obras concebidas no período abril-maio de 1946 é óleo sobre tela denominado Anagogie, datado em agosto de 1947. Nele há duas imagens enigmáticas acompanhadas de uma ave de concepção próxima a um pato. Apenas a figura que se encontra na parte superior à direita está próxima da personagem de Taça. A obra possui também o corpo dobrado como em O Triunfo da Dúvida. No que se refere às linhas da cabeça que formam o rosto, suas dimensões são as mesmas encontradas no quadro do Masp. No caso dessa tela, o destaque é para a construção das mãos da personagem indicada, que é semelhante à forma geometrizada das mãos da personagem de Taça.

O modo como as duas cabeças são fundidas na figura de Taça da Dúvida não encontra similar em nenhuma outra obra de Brauner8. A presença de um animal ao lado da personagem não é observada nesse contexto. No segundo quadro de abril de 1946, com a figura "masculina" esboçada à direita da personagem, Brauner parece sugerir uma necessidade de colocar um acompanhante, que um mês depois surgiria como um cão. É verdade que em Anagogie encontraremos um animal, mas 
nessa tela o assunto parece ser de outra natureza, e as semeIhanças são apenas de caráter formal.

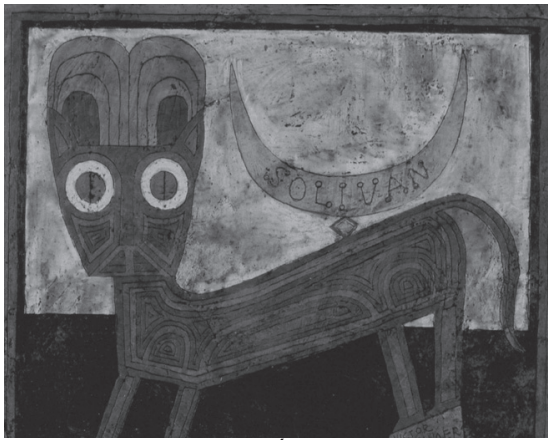

Fig. 8 - Solivan, 1946. Óleo recoberto com cera e incisões de nanquim. $22 \times 27,4 \mathrm{~cm}$. M.N. A. M., Paris.

A primeira aparição, com destaque, para algo semelhante a uma taça, está num quadro chamado Projet pour Stable, Instable, de 1941. Mas, mesmo nesse quadro, a "taça" não possui semelhanças formais com o objeto encontrado nos trabalhos de 1946 (Taça da Dúvida e no quadro Sem Título de abril). No sentido contrário, podemos indicar quadros como Solivan de 1946, em que na cabeça do gato reproduzido surge uma forma muito semelhante a uma fonte (fig.8), mas aqui existe apenas uma semelhança formal que, com muitas ressalvas, pode ser justificada. Para não incorrer no erro de uma mera relação formal ou de simples evocação de um conteúdo que pouco pode nos esclarecer sobre a produção de Taça, preferimos conciliar as duas análises possíveis, ressaltando aquelas obras que possuem elementos semelhantes a de uma taça e que são animadas por uma fonte-seios. Para isso dois trabalhos são fundamentais: Coupe des Cent-Vingt Dispostions erotomagiques, de 1946, e Le Feu et l'Eau de I'amour, de 1945. Ambas produzidas com a técnica a cera.

Não podemos apontar uma taça na obra Le Feu et l'Eau de l'amour. Este quadro é a prova da rápida evolução que Brauner obteve com sua técnica a cera. Trata-se de uma das primeiras obras produzidas no seu retorno a Paris, após a desocupação nazista de 1945. O quadro é datado de março deste mesmo ano e pode significar, entre outras coisas, uma certa felicidade de voltar a Paris após os anos na Suiça. Dor pela carnificina promovida pela humanidade e alegria para aqueles que sempre defenderam o seu fim. Uma luta entre sentimentos ambíguos que marcam o final da ocupação e da guerra.

Para tratar do amor, Brauner pintou três personagens. Duas, localizadas nas extremidades do quadro, corporificam o fogo (à direita), como indica sua cor vermelha, e a água (à 
esquerda), representada em tom de azul. São duas figuras "humanas" desenhadas do modo mais usual de Brauner, queixo alongado, nariz proeminente, enfim, linhas simples. No meio há a figura que nos interessa. Trata-se de uma imagem dupla. Nela podemos ver "uma fonte" cuja base não deve ser confundida com a de uma taça, que jorra um líquido. No eixo principal dessa fonte, está representada uma boca e, mais no alto do mesmo eixo, dois olhos. O que nos chamou a atenção é a presença formal da fonte. Ela possui o mesmo princípio de traços que formam a taça-fonte do Masp, no seu interior. Outro ponto é a simetria da fonte. Mas essas semelhanças formais não mereceriam destaque se o conceito da imagem dupla não estivesse presente nessa obra. Tal conceito possui uma história muito antiga para que nela nos detivéssemos. Porém, o modo como foi articulado em ambas as obras (Taça da Dúvida e Le feu et l'eau de l'amour) coloca essas duas pinturas como parentes próximos. As imagens duplas surgem de uma fonte, estão no centro dos quadros e ambas personificam uma relação misteriosa que poucos podem determinar com certeza.

No início de 1946, Brauner já estava instalado no seu novo ateliê na rua Perrel. Foi nesse endereço em Paris, que também serviu a Douanier Rousseau, onde Brauner ocupou-se de produzir, entre outras, Coupe des Cent-Vingt dispositions erotomatiques (fig.9), obra datada de janeiro de 1946. O que encontramos no quadro é mais uma imagem dupla, pois Brauner pinta uma "taça" como se fosse uma cabeça. Sobre essa "taça" encontramos um artefato decorativo que serve como apoio para quatro serpentes. A composição é mais uma obra que está intimamente ligada à idéia de arcaísmo que Brauner possui. Uma idéia muito presente, segundo ele, no nosso "eterno cotidiano mágico" (JOUFFROY, 1995,

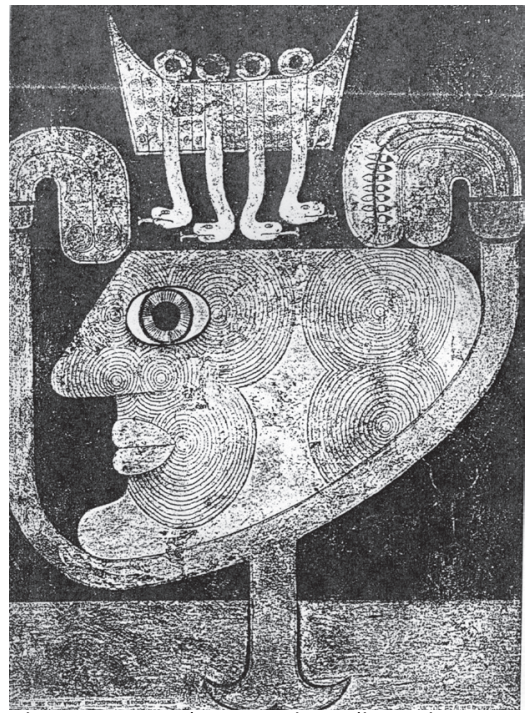

Fig. 9 - Coupe des cent-vingt dispostions Erotomagiques, 1946. Óleo e cera sobre madeira. 66 × 52,1 cm. Coleção Particular. p.17). Nesse quadro, a taça representa uma 
natureza mística que, como o nome da obra indica, possui uma conotação sexual muito forte. A presença das serpentes não é em si uma novidade; Brauner utiliza-se delas desde 1941. Para autores como Semin (1990), é quase uma assinatura do pintor. No que toca às questões mais formais, o quadro pintado meses antes que Taça da Dúvida traz a confirmação do modo como Brauner, naquele momento, estava produzindo o rosto em perfil com uma característica de economia de traços. Outra semelhança com a obra do Masp é que, no quadro de janeiro, há, também, um "campo" que sai do pescoço e envolve a cabeça. Como aqui, trata-se de uma figura produzida dentro de uma ótica da imagem dupla, onde esse mesmo "campo" é a haste da taça.

Para completar, vamos retornar ao primeiro desenho sem título datado de 07 de abril de 1946 (fig.6). Nele encontramos uma taça suspensa do lado esquerdo da cabeça da personagem, conforme já comentamos. Da taça jorra um líquido que parece estar aquecido por uma vela disposta embaixo da taça. O modo como Brauner construiu essa imagem é revelador para a compreensão da função da vela na cabeça do cão em Taça da Dúvida. Esta vela pode ser, como no quadro de abril, um catalisador do líquido que jorra da taça, mesmo que a disposição dos objetos, taça e vela, não nos indique isso. A unidade conceitual dos dois artefatos parece proceder de uma relação simbólica entre ambos, que remete a uma iconografia cristã e pagã. Cristã na medida em que a taça surge como elemento receptáculo da essência da vida (o sangue de Cristo, por exemplo), e a vela como indicador da presença de Deus, estratégia fartamente utilizada desde a Alta Idade Média. Pagã porque os objetos não estão isolados de suas potências geradoras, a taça liga-se ao seio que gera e deseja, e a vela cria um paralelo com falo ereto do cão: potência, vontade e desejo.

\section{Alguns masculinos}

Se o pintor alemão Franz Marc (1880-1916) entrou para a história das vanguardas do século XX como um artista que pintava animais, certamente Brauner e outros como Max Ernst 
(1891-1976) podem entrar para a história como "animalizadores" das mais diversas cenas do drama humano. Animalizar é um modo de "significar" como Brauner encarava a natureza e, sobretudo, os animais. Para Brauner, aqueles são os mais próximos modelos de conduta do espírito humano. Em toda a história das místicas e do sagrado, eles são evocados para sintetizar e simbolizar o sobre-humano. Trata-se de uma força, além da humana, que dota todos os homens de uma natureza próxima à do animal. Parece-nos que Brauner evolui na sua obra para o apagamento das diferenças entre homens e animais, pois todos comungam do mistério. É nessa ótica que Brauner cria os mais diferentes tipos de fusões entre homens e animais9 e representa ora um, ora outro, de maneira a ressaltar a transgressão dos limites que separam seres humanos e o resto da natureza.

O cão de Taça da Dúvida é uma criatura titânica com sua língua incisiva e seu sexo ereto. É sobre ele que está a vela. Esse pequeno objeto que pode mover o "espírito" da taça que jorra. O pequeno cão, que pode ser um protetor, é constituído de formas geométricas da mesma natureza que o motivo decorativo na cabeça da figura feminina. São linhas controladas, que criam estratos que delineiam a sua cabeça, o pescoço e a parte de trás de seu tronco. Este último é formado por pequenos traços que se multiplicam, criando um fluxo ascendente e descendente.

A semelhança formal deste cão com o gato de Solivan (fig.8), obra datada de 28 de abril de 1946, é grande. O felino foi pintado dias antes que o cão (Taça da Dúvida é datada de 2 de maio). Em Solivan, o gato é a figura principal. Ele está acompanhado de uma meia-lua invertida, signo cabalístico dos mistérios negativos da noite (BUBER, 1963, p.142). O felino também é composto por formas geométricas que compõem estratos que o delimitam. A semelhança desse modo de constituir os seres guarda relações com a cerâmica e a tapeçaria polinésia.

As cores não parecem uni-los. Isto porque, no gato, predomina azul, rosa e tons de verde, enquanto, no cão, há predominância de laranja e de tons de vermelho. Outro ponto em que são diferentes é à atitude. O gato parece assustado e passivo, 
seus olhos são representados com branco10 e ocre; o cão, por sua vez, é uma figura agressiva e ativa.

Le Chasseur de I'Inconnaissance, de julho de 1949, é um outro quadro, mesmo posterior, que deve ser citado quando se trata da representação de cães. Nessa obra a óleo, produzida numa outra fase de Brauner, podemos ver um cão ao lado de uma personagem que, em uma das mãos, possui um arco e, na outra, uma espécie de flecha na forma de um falo. Esse animal é delineado com traços grossos e, mesmo que seu corpo tenha sido composto com formas geométricas, essas não são da mesma natureza estrutural que o gato de Solivan e o cão de Taça. A justificativa para sua menção em nossa análise é o fato de que a representação do cão ao lado de uma personagem humana só pode ser encontrada em Taça. e nesse quadro.

Brauner poderia ter representado o cão sem definir seu sexo ereto11, como, aliás, chegou a fazer em Le Chasseur de I'Inconnaissance, em 1949. O porquê dessa referência numa obra e não em outra é uma questão difícil de se responder tendo como fonte apenas as obras. Doravante, o que podemos é apontar, na produção de Brauner até 1946, quais as obras mais importantes do ponto de vista erótico e delas retirar conclusões no sentido de como o seu erotismo foi organizado.

A primeira obra que devemos citar é sem dúvida uma obra singular. Ela une duas obsessões surrealistas e duas buscas particulares de Brauner: o olhar e o sexo. Le Monde Paisible de 1927 (fig.10), uma obra a lápis e nanquim sobre o papel, é um desenho em que se pode encontrar um corpo representado da cintura para baixo e onde, no lugar do sexo, há um olho. Nessa pequena obra, Brauner desempenha sua capacidade de deslocar partes da anatomia humana sem que essa atitude retire da parte alterada sua sugestão original. Como acontece nesse caso, o pintor não deixa de fazer das pál-

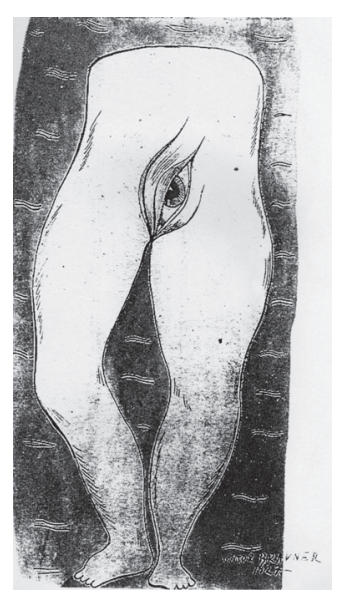

Fig. 10 - Le Monde

Paisible, 1927. Nanquim e lápis sobre papel, 17,2 x 
pebras do olho uma referência direta aos contornos do sexo feminino12.

Petite morphologie, obra a óleo de 1934, é uma intrigante obra erótica que parece declarar que o sexo é antes de tudo uma atividade autônoma, um ser que vive como nós. A obra está dividida em duas partes. Na superior, Brauner pinta quatro pequenas figuras que aparentam significar seres humanos, na parte de baixo, ele pinta quatro órgãos genitais como se fossem seres humanos, com os membros, o tronco e cabeça. O sexo aparece aqui como um ser retratado em igualdade de condições com qualquer configuração humana. Brauner poderia ter visto nessa obra um modo de conceder ao sexo o papel de
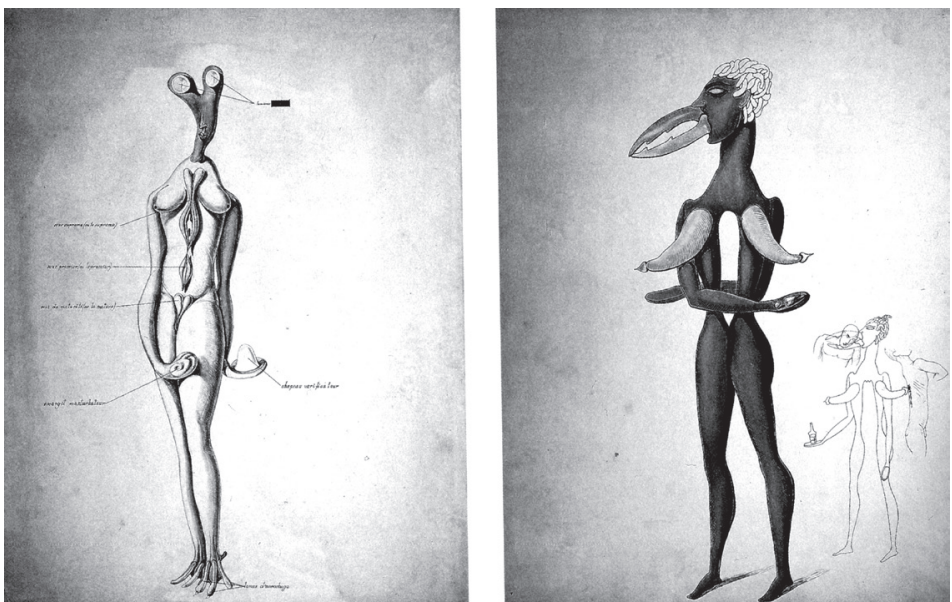

Fig. 11 - Anatomia do Desejo, 1935-36. Nanquin, giz e lápis sobre papel, 65,5 x $50 \mathrm{~cm}$. M.N.A. M.,Paris. (2 exemplares)

simbolizar o ser humano, tão legítimo quanto qualquer outra particularidade ou construção humana.

No caso da efetiva representação do corpo feminino nada pode comparar-se à série de desenhos Anatomia do Desejo (fig.11), de 1935 e 1936. Esta série é o exemplo de como Brauner organizou suas visões eróticas nos anos 30. Os desenhos são formados por corpos femininos superdotados de atributos sexuais. A anatomia desses corpos está visualmente relacionada com a adesão de diferentes estruturas, como torneiras, alicates, tesouras, maçanetas, rabos etc. Estas estruturas, na sua maioria mecânicas, tornam-se orgânicas na medida em que es- 
tão ligadas às partes dos corpos dessas mulheres e pelo modo como o pintor realiza essa ligação, sem conceder espaço para rupturas. Isto é parte de seu talento como desenhista. O intuito do pintor é de sugerir que esses artefatos nos corpos femininos possam ser utilizados como pontos de apoio para fixação provisória dos corpos masculinos.

As deformações têm sua razão para existir. Brauner cria mulheres devoradoras, perigosas e luxuriantes. Ele mesmo diz que seu objetivo é apreender a mulher no seu gozo máximo, no momento em que a cabeça deixa de ser o centro do corpo, e o sexo assume o domínio, como puro prazer:

Au moment du coït et surtout de l'éjaculation elle tranchera avec ses lèvres géantes et coupantes le corps de l'homme et ce spasme de la mort lui procurera une joie érotique considérable tout en suçant avidement son sang. Elle gardera le cadavre en l'entrelaçant toute la nuit dans ses bras et le sexe plus vivant que jamais en état d'érection pour toujours. Pour l'homme la joie était aussi la plus grande de sa vie (CENTRE GEORGES POMPIDOU, 1996, p.63).13

Não há prazer sem dor? Para o erotismo de Brauner, não. Basicamente porque o prazer é um limite, é o mais próximo da morte e só pode ser vivido na sua totalidade quando ultrapassa as censuras internas, e realizar tal tarefa é desconfortável, doloroso. Nessa maneira romântica de encarar o amor, o desejo e o objeto erótico, há, sem dúvida, um forte potencial de sadismo (GAUTHIER, 1971, p.54-56). As mulheres de Anatomia do Desejo podem muito bem ilustrar qualquer manual de sadomasoquismo contemporâneo. Brauner parece querer dar um rosto a sua anima (JUNG, 1964, p.31). São seres em total êxtase, instrumentos de prazer e dor em pleno estado de ativação. Elas não são passivas nas fantasias artísticas do pintor. Nessa direção, numa provocação interpretativa, os seios de Taça, o gozo parece-nos como uma fonte assentada sobre o sexo da personagem.

Esse estado de ativação permanente ("d'érection pour toujour") das potencialidades sexuais é a sua marca quando se trata da representação da virilidade masculina. O sexo masculino está, na grande maioria das obras estudadas, ereto. Como nas 
civilizações antigas, o falo ereto é símbolo do poder masculino. Brauner parece ver nele a vitória do inconsciente sobre a razão; sua força e sua energia canalizadora para o prazer e para a vida no prazer. Esse modo de representar o sexo masculino está em Prestige de l'air, de 1934, com seu pênis mecanizado. Também aparece nas obras onde Mr. K., obra- prima dos anos 3014, como no cão de Taça da Dúvida.

A evolução dos motivos eróticos de Brauner após 1946 é coerente com a evolução de seus valores. Após esse período não encontramos apenas seres femininos e masculinos isolados, mas, sobretudo, eles aparecem juntos em cópulas frias e coreografadas. Obras como S'initiant à la sodomie e À I'hypercoït barbarogène, ambas de 1949, são referências óbvias ao sexo anal e oral entre seres mutantes e enigmáticos, seres que são representantes diretos do inconsciente coletivo delineado pelos olhos de Brauner.

Um ponto comum entre todas essas obras citadas e o quadro que estamos estudando é a caracterização dessas imagens como aparições antigas. Brauner utiliza com efetiva maestria sua técnica e o seu estilo para conceder a cada signo uma idade remota. É como se um mesmo ritual fosse representado por séculos e cada geração fizesse uma leitura nova desse rito. Uma nova taça, um novo olhar, uma nova forma que, no fundo, partem de uma mesma matriz: o sonho e a magia.

\section{Do sagrado}

Taça da Dúvida é uma obra que nos deixa muito pouco confortáveis para apontar ou priorizar uma direção simbólica precisa diante dos exemplos de parentescos formais apontados acima. Seu caráter parece-nos ser de eminente síntese. Brauner não deixou de invocar o velho arquétipo da mater e, por conseguinte, uma incalculável tradição representativa. Contudo, como no caso de seu par do Masp - Arquitetura Pentacular -, Taça parece-nos comprometida com a tradição da cabala e dos signos alquímicos. A novidade neste caso é o seu caráter egipício-bizantino. A personagem da obra está à vontade com o fundo dourado. A cor pomposa e imperial vem reforçar a 
majestade desta dama, colocá-la ao lado de uma tradição de rainhas, deusas e ninfas que provêm com seu leite à fertilidade da terra.

É de Ravena o famoso mosaico de San Vitale, denominado A Imperatriz Teodora e seu séqüito (fig.12), do

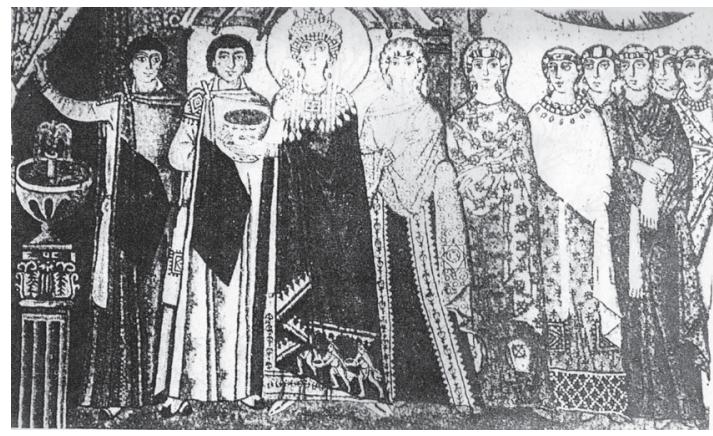

Fig.12 - A Imperatriz Teodora e seu séqüito. Mosaico de San Vitale em Revena, Itália, do século VI d.C. século VI d.C., o qual Brauner certamente conhecia e no qual podemos encontrar algumas mostras do quanto a tradição bizantina pertencia ao vocabulário do artista. Nessa magistral obra-prima do período encontramos uma solene e digna mulher (Teodora), levemente deslocada para a esquerda, segurando uma taça (ou seu par masculino: um cálice). Esta atitude, este gesto é uma das contribuições para a construção de um repertório gestual, no qual cada ato pode simbolizar uma hierarquia, um status social e uma função social e mística.

No extremo esquerdo do mosaico, no mesmo campo de visão das demais personagens, existe uma fonte-chafariz, cujas formas são muito semelhantes ao conjunto taça-fonte-seios de Taça. As semelhanças não são peremptórias. Não completam nenhum quadro definitivo, nem esboçam qualquer herança entre as obras, mas indicam o vasto vocabulário que Brauner podia acionar.

Reforça nossas desconfianças a atração do artista pelas cartas do tarô, que, não por acaso, são as grandes mantenedoras daquela escrita gestual e simbólica consagrada pelos mosaicos bizantinos e por uma iconografia clássica mediterrânea.

Ainda na esfera bizantina, como já citamos, está a predileção pelo dourado. Nesta tradição, o ouro é a imagem da luz solar, ou seja, a inteligência daquilo que nos é superior, o divino. O ouro é a cor da majestade, do mais alto, a glorificação 
do perfeito, o antônimo do negro (a culpa e a penitência). Na obra de Brauner, o dourado geralmente duela com o negro (em Taça uma variação de marrom escuro). O ouro surge como se estivesse sendo revelado por detrás do negro, ambos como forças complementares que se misturam. Relações cromáticas caras à tradição do ícone bizantino15.

Esta mística fala através da imagem santificada do ícone, que é liturgia, discurso. Sabemos que a tradição da ortodoxia cristã16, herdeira imagética de Bizâncio, concede às visões uma certa primazia. Os mosaicos e as pinturas dos ícones são exemplos de Luz segundo essa tradição. Toda a teologia tem uma tradição e uma parte de sua evolução na constituição da imagem. E falar de ícone é falar de profecia. Segundo Sers \& Yon (1990), é por essência uma arte profética. A imagem profética é, por sua vez, imagem mistérica, é a manifestação de uma revelação, de uma visão. A imagem profética é crucial para a materialização do ícone, e quem é o profeta senão um místico que está em contato com algum Ser.

Longe de ser uma conclusão, Taça da Dúvida configura-se como uma das obras-primas de Brauner justamente por sintetizar o artista profeta - representação de si cara a Brauner, como vimos - e a necessidade de aliar antigas representações com um novo vocabulário moderno. Taça, ao lado de suas pares, significa, em sua imobilidade e aparente passividade, uma forma da medida de todas as coisas: o potencial de violência sexual, a destruição e a criação fértil. A dúvida que suscita não pode ser respondida pela métrica exata. Amuleto xamânico, tarô moderno, índice cabalista, ícone surrealista, fábula alquímica, Taça da Dúvida é, sobretudo, apenas uma pista da vasta escrita simbólica de Brauner, artista ambicioso que pretendia, a seu modo e face, conferir ao mundo um novo e moderno vocabulário místico.

\section{Notas}

1. Informações documentadas na pasta $n . \circ 163$ do arquivo do MASP.

2. Pouco se diz sobre uma possível e provável influência da arte de Picasso, principalmente daquela apresentada após 1928. Exceção para o texto de Margaret Montagne ("The Myth of de Double") para uma exposição internacional em 2002 (apud DAVIDSON, 
2002, p.43-56).

3. A obsessão pelo olho dilacerado possui um importante marco na história do surrealismo: a cena do olho cortado por uma lâmina no filme Um cão andaluz, de Buñuel e Dali de 1928. Antes dela, toda uma literatura mística apropriada a partir dos românticos alemães (CAIEIRO, 1995).

4. "Pode-se evidentemente perguntar-se porque os olhos chamam o mistério interior de um ser. Mas o olho é certamente a coisa mais enlouquecedora: ele guarda a chave do mistério do ser (...) É o olhar que é a coisa mais perturbadora". Tradução livre do autor.

5. "O homem que eu conheci antes do acidente era apagado, tímido, pessimista, desmoralizado por sua última passagem pela Romênia; ele está atualmente liberto, afirmando com clareza e autoridade suas idéias, trabalhando com um vigor novo e alcançando mais sua meta", Tradução livre do autor.

6. É necessário salientar que essa relação com a representação dos olhos está, geralmente, acompanhada de um antropomorfismo. Podemos ver nessa relação uma influência das artes primitivas tanto quanto da leitura que Brauner faz do antropomorfismo de Max Ernst.

7. Do mesmo mês de Taça da Dúvida, datado no dia 2. Infelizmente a indicação da data na reprodução que possuímos de $\mathrm{O}$ triunfo da Dúvida não é legível.

8. Excluindo tal possibilidade na infinidade de desenhos que ainda não foram publicadas e que pertencem ao Arquivo Victor Brauner do Centre Georges Pompidou.

9. Exemplos dessas fusões podem ser fartamente encontrados nos desenhos que formam o Cahier Très Belle L'or e o Cahier Bleu, ambos de 1941. Estes cadernos pertencem ao Museu Nacional de Arte Moderna da França.

10. Em nossa pesquisa raramente encontramos o branco quando a obra é produzida com a técnica a cera.

11. O cão em Taça Dúvida lembra-nos as premissas alquimistas que acreditavam que "le chien dévoré par le loup represente la purificacion de l'or par l'antimoine, avant-dernière étape du grand-oeuvre." (CHEVALIER \& GHEERBRANT, 1988, p.241). A dicotomia lobo-cão é antiga na produção de Brauner, data do inicio dos anos 20.

12. Deslocar órgãos para a aquisição de um efeito erótico não é uma novidade introduzida por Brauner. É difícil determinar o início desse modo particular de representação na arte surrealista. Mas, além de Brauner, Magritte sempre utilizou esse efeito estético na sua arte, como podemos observar em quadros como $\mathrm{O}$ conhecimento natural, produzido nos anos 20, e O Estupro, de 1934. Neles os seios tomam o lugar dos olhos, e o sexo, da boca.

13. "No momento do coito e, sobretudo, da ejaculação, ela cortará com seus lábios gigantes e afiados os corpos dos homens, e esse espasmo da morte lhe proporcionará uma alegria erótica considerável, sugando avidamente seu sangue. Ela guardará o cadáver entrelaçando-o toda noite em seus braços e sexo e mais vivo que nunca num estado de ereção perpétua. Para o homem a alegria seria assim a maior de sua vida.", tradução livre.

14. Nesse caso o pênis é representado em suas dimensões normais, o que, ao modo de Brauner, é uma anedótica maneira de retratar o homem burguês, pois o sexo dos seres masculinos geralmente são super-dimensionados.

15. O ponto de partida para pensar o ícone é a qualidade da cor. A partir daí, estabelecemos a espaço-temporalidade do elemento colorido e sua morfogonia. O contraste entre o quente e o frio que proporciona a dimensão espacial. Como Sers e Yon (1990) nos apresentam, o contraste do claro-escuro, tendência ao branco ou ao preto, confronta-nos com a dimensão temporal do percurso: o branco contém todos os possíveis, silêncio de antes do nascimento, e o preto os encerra, silêncio após a morte. Enquanto o ouro é atemporal, pretende a eternidade. 
16. O país natal do pintor está na rota de uma longa tradição ortodoxa que não polpa nem mesmo os não cristãos. Não podemos esquecer que Brauner nasceu nessa tradição artística moldada pela liturgia do cristianismo ortodoxo que é, sobretudo, uma liturgia dupla, fundamentada na palavra e na imagem. O ícone não estava destinado a representar nada deste mundo. Era uma tentativa de exprimir o inefável. Como explica o historiador inglês Peter Brown: "Por todo o mundo cristão oriental, ícone e visão validavam-se um ao outro, Uma profunda concentração num ponto focal da imaginação coletiva. (...) fez com que no século VI o sobrenatural já houvesse adquirido linhas preciosas, em sonhos e na imaginação de cada pessoa, em que comumente retratado na arte. O ícone tinha a validez de um sonho realizado" (apud ARMSTRONG, 1994, p. 212).

\section{Referências}

ALEXANDRIAN, S. Le surrealisme et le rve. Paris: Edition Gallimard, 1974. ARMSTRONG, K. Uma histria de Deus: quatro milênios de busca do Judaísmo, Cristianismo e Islamismo. Trad. de Marcos Santarrita. São Paulo: Cia das Letras, 1994, 460p.

BRETON, A. Le surralisme et la peinture. Paris: Ed. Gallimard, 1979. Manifestos do surrealismo. Trad. de Luiz Forbes. São Paulo: Editora Brasiliense, 1985.

Arcano 17. Trad. de Maria Teresa de Freitas e Rosa Maria Boaventura. São Paulo: Brasiliense, 1986 Les pas Perdus. Paris: La Pléiade, 1988.

BUBER, M. Les rcits hassidiques. Paris: Plon, 1963.

CAIEIRO, O. Oito sculos de poesia alem. Lisboa: Fundação Calouste Gulbenkian, 1995.

CENTRE GEORGES POMPIDOU. Victor Brauner. Paris, 1996. Catálogo de exposição individual.

CHEVALIER, J. \& GHEERBRANT, A. Dicionrio de Smbolos: mitos, sonhos, costumes, formas, figuras, cores, números. Rio de Janeiro: José Olympio Editora, 1988.

DANCER, M. "Victor Brauner ... Ici, ou j'ai tant désiré Être" In: Viktor Brauner. Musée d'Art Moderne Saint-Etienne. Galerie HL. Mesta Prahy, 1996.

FOCILLON, H. Vie des formes. Paris: Quadrige/PUF, 1984.

GAUNT, William. Los surrealistas. Barcelona: Ed. Labor, 1974.

GAUTHIER, X. Surralisme et sexualit. Paris: Gallimard, 1971.

JOUFFROY, A. Victor Brauner: le tropisme totémique. Paris: Dumerchez, 1995.

Victor Brauner. Paris: Fall Edition, 1996.

JUDLOVÁ, M e ROUSOVÁ, H. Victor Brauner: a wolf from the Carpathian Mountains in Paris. New York: The Museum of Modern Art, 1996. 
JUNG, C. G. O homem e seus smbolos. Trad. de Maria Lúcia Pinho. Rio de Janeiro: Nova Fronteira, 1964.

SEMIN, Didier. Victor Brauner. Paris: Réunion des Musées Nationaux-Édition Filipacchi, 1990.

SERS, P. \& YON, E. Les saintes icnes. Denöel: Paris, 1990.

VANCI-PERAHIM, M. "Victor Brauner na Roumanie". In: Victor Brauner, 1903-1966, Milão: Galleria Schwarz, 1995.

\section{EMERSON DIONISIO GOMES DE OLIVEIRA}

Mestre em História da Arte e da Cultura pela Unicamp; ex-diretor e curador do Museu de Arte Contemporânea de Campinas. Atualmente é doutorando em História pela Universidade de Brasília, onde pesquisa acervos de museus regionais de arte contemporânea sob orientação da Profa. Dra. Eleonora Zicari Costa de Brito, com apoio do CNPq.

Email: emerson_dionisio@hotmail.com 